\title{
Pumps layouts in single hydraulic unit of aircraft thermocontrol system
}

\author{
Bobkov A. \\ Department of aircraft \\ Komsomolsk-na-Amure State University \\ Komsomolsk-on-Amur, Russian Federation \\ bobkov@knastu.ru
}

\author{
Makarov K. \\ Department of aircraft \\ Komsomolsk-na-Amure State University \\ Komsomolsk-on-Amur, Russian Federation \\ prnir@knastu.ru
}

\author{
Shport V. \\ Department of aircraft \\ Komsomolsk-na-Amure State University \\ Komsomolsk-on-Amur, Russian Federation \\ office@knastu.ru
}

\begin{abstract}
The usage of unified devices in the spacecrafts and aircrafts allows reducing the cost of their production, but at the same time leads to the problem of unified device characteristics harmonization with systems of a unit under design. In on-board aircraft thermocontrol systems, which ensure given temperature conditions, two unified centrifugal pumps being combined in a single hydraulic unit are often installed instead of one pump in order to provide the force circulation of coolant over the system circuit. Hydraulic unit housing acts as a base component combining two pumps into a single unit. Additionally, inlet and outlet unions common for two pumps for connection to the thermocontrol system pipelines are located in the hydraulic unit. Such a structural solution reduces a number of sealed joints, weight and sizes of inlet and outlet channels. The article represents technical characteristics of spacecrafts' unified centrifugal pumps and considers selection criteria of pumps layout in a single hydraulic unit of the thermolcontrol system. Harmonization diagrams of hydraulic characteristics of the thermocontrol system and hydraulic unit pumps are represented. Their design features are considered.
\end{abstract}

Keywords-system of thermoregulation of space vehicle; hydraulic unit.

\section{INTRODUCTION}

On board, thermocontrol systems (TCS) of spacecrafts (SC) and aircrafts (AC) are intended for ensuring allowable temperature conditions for equipment and structural components operation [1-5].

For example, heat impact of the Sun and the Earth radiation fluxes on spacecraft is (140...420) W per square meter of a craft midsection area. Temperature of a spacecraft's dayside housing surface can reach up to $+60^{\circ} \mathrm{C}$ and temperature of nightside housing surface can fall down to $-80^{\circ} \mathrm{C}$. In a sealed internal section of SC operating equipment and crew release thermal energy. Within 24 hours, total value of thermal energy varies from a few hundred watts to several kilowatts.

In $\mathrm{AC}$ when heat release from equipment being cooled exceeds $1 \mathrm{~kW}$ of heat rate, an active hydronic TCS are used. The characteristic "active" TCS means force circulation of coolant by centrifugal pumps.

Usually, the design process of active TCS comprises stages of conceptual design and detailed design. At the stage of conceptual design, technical documentation containing essential structural solutions, which particularly allow assessing main technical parameters and components composition of AC TCS under design [6].

At the stage of detailed design, the package of engineering documents is developed. It contains detail, assembly, mounting and dimensional drawings, electrical diagrams, etc. At this design stage, the following requirements for TCS structure are observed:

- The system shall be operationally reliable with high performance coefficient at the design mode and the whole range of operational modes.

- Weight and dimensions of the system structure under design shall be minimal. Strength properties of applied materials shall be used to the maximal extent and strength reserves shall be minimal but sufficient in order to ensure reliable operation;

- TCS structure shall be designed for determined period of operation. Service life shall be determined by the Technical Assignment;

- TCS components shall be easily producible and the structure of discrete component shall be adaptable to production using current process equipment with minimal cost.

Policy of devices and components standardization and unification is a part of rational design. Standardization of operating parameters and standard sizes of pumps being used in TCS allows creating the line of centrifugal pumps of different capacity containing the same unified parts. Unification of the centrifugal pump design simplifies production process, reduces 
the amount of necessary outfit and special tools and significantly reduces costs and product campaign.

Basing on engineering documents, samples are produced and tests are carried out. Assessment of the unit operation capacity and the compliance of its technical and operation characteristics with the Technical Assignment requirements is performed.

\section{STANDARDIZED PUMP CONFIGURATION}

\section{A. Electric Drive}

Many types of pumps are used in instrument systems [7]. In thermoregulation systems, centrifugal pumps are most often used [8]. TCS standardized centrifugal pumps are fitted with DC drive that comprises three elements [9], refer to Fig. 1:

- Brushless motor with stator m-phase windings and excited rotor;

- Rotor position sensor that generates control signals to determine windings switching time instant and sequence;

- Static switch that switches current between the stator windings by signals from the position sensor.

The switch consists of semiconductor elements and is fitted in an individual box connected to the motor by a plug.

\section{B. One-Piece Pump}

For aircraft TCS, standardized pumps have one-piece design. In this case, the pump impeller (1) is mounted on the rotor (2) outlet part, refer to Fig. 2. Due to one-piece design, the rotor is submerged in fluid. Therefore TCS standardized pumps are fitted with brushless DC semi-wet motors. To couple the pump impeller (1) to the motor shaft, it is not required to fit an end seal and seal the gap between the rotor and motor shield.

\section{Electric Motor}

The motor rotor (2) (Fig. 2) is a permanent magnet rotor. The motor stator (3) is an iron stack. The stack holds windings. Shield (6) between the rotor and stator is a non-magnetic stainless steel cylinder connected and sealed to the motor housing. The shield is pressed against the inner surface of the stator. Efficiency of shielded motors is lower comparing to regular motors due to additional losses through the shield and gap between the rotor and stator. The gap can be $0.8 \cdot 10-3 \mathrm{~m}$ together with the shield thickness.

The motor housing also accommodates the position sensor consisting of the rotor (4) and stator (5). The sensor rotor is a segment (bevel-edged cylinder) coupled to the motor shaft. The sensor stator has sensitive elements. Their quantity is equal to the number of windings and position corresponds to the windings. Sensing elements can be a Hall effect sensor or magnetic diode.
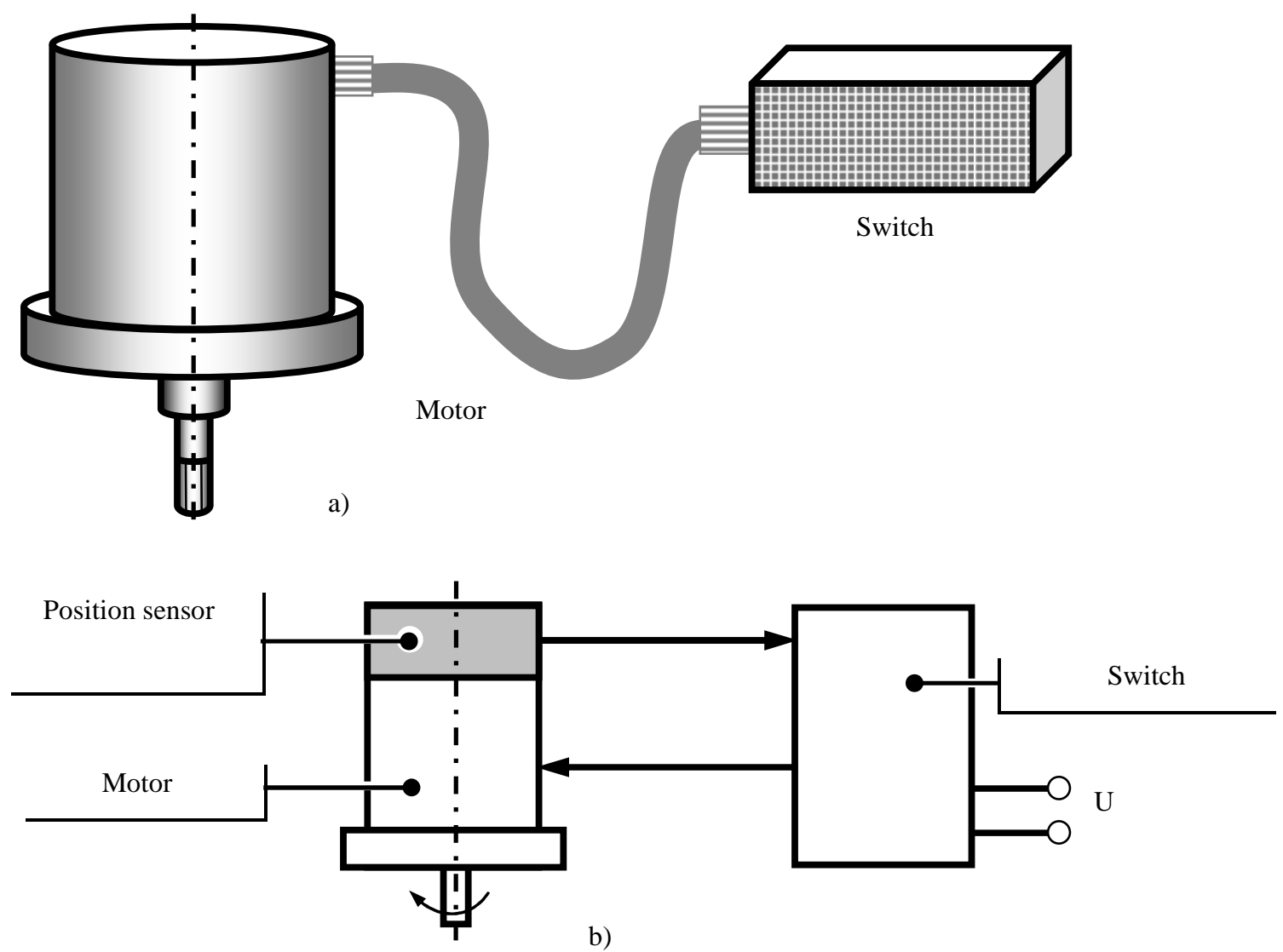

Fig. 1. Pump Electric Drive: a) General view; b) Electric drive schematic diagram 


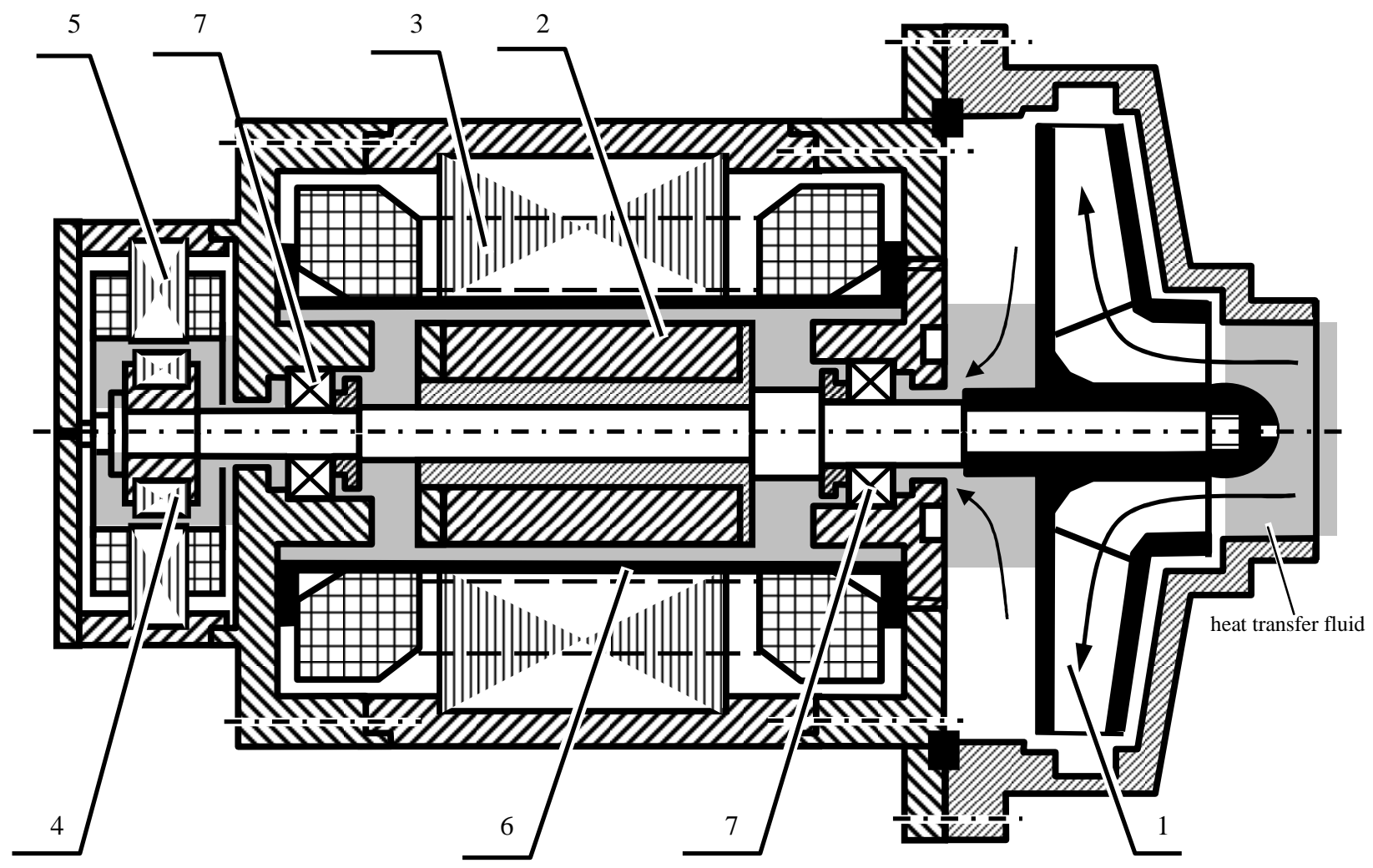

Fig. 2. One-Piece Standardized Centrifugal Pump: 1 - Centrifugal pump impeller, 2 - Motor rotor,

3 - Motor stator, 4 - Position sensor rotor, 5 - Position sensor stator, 6 - Shield, 7 - Antifriction bearing

The signal cell triggers control signals to the switch.

\section{RESULTS AND DISCUSSION}

Table 1 [10] represents operating parameters of unified centrifugal pumps of TCS. Parameter ranges are as follows: coolant rate $\mathrm{Q}=(80 \ldots 130) \cdot 10-6 \mathrm{~m}^{3} / \mathrm{s}$; intake power $\mathrm{N}=(4 \ldots 40)$ $\mathrm{W}$; rotary speed $\mathrm{n}=(2800 \ldots 4500) \mathrm{rpm}$; service life - from 25000 to 50000 hours.

TABLE I. TECHNICAL CHARACTERISTICS OF UNIFIED CENTRIFUGAL PUMPS OF SC TCS

\begin{tabular}{|c|c|c|c|c|c|}
\hline \multirow{2}{*}{$\begin{array}{c}\text { Symbol } \\
\text { ic } \\
\text { Notatio } \\
\text { n } \\
\text { Pump } \\
\end{array}$} & \multicolumn{5}{|c|}{ Technical characteristics } \\
\hline & $\begin{array}{c}\text { Electrical } \\
\text { motor }\end{array}$ & $\begin{array}{c}\text { Rotary } \\
\text { speed } n, \\
\text { rpm }\end{array}$ & $\begin{array}{c}\text { Coolant } \\
\text { rate } Q, \\
m^{3} / s\end{array}$ & $\begin{array}{c}\text { Intake } \\
\text { power } N, \\
W\end{array}$ & $\begin{array}{c}\text { Operationa } \\
\text { l life } t, \\
\text { hours }\end{array}$ \\
\hline $2428-0$ & BEP-121G & 4500 & $10^{-4}$ & 25 & 44000 \\
\hline $2125-0$ & DB9/K30 & 4900 & $13 \cdot 10^{-5}$ & 22 & 50000 \\
\hline $4430-0$ & BEP-121G & 4800 & $12 \cdot 10^{-5}$ & 22 & 44000 \\
\hline $2237-0$ & BPS-202 & 2800 & $80 \cdot 10^{-6}$ & 14 & 25000 \\
\hline $2428-0$ & BEP-121Г & 4500 & $10^{-4}$ & 25 & 44000 \\
\hline
\end{tabular}

TCS pump ensures circulation of heat transfer fluid (with flow rate $\mathrm{Q}, \mathrm{m} 3 / \mathrm{s}$ ) over the system hydraulic circuit overcoming the hydraulic resistance estimated by pressure losses $\mathrm{Phr}\left(\mathrm{N} / \mathrm{m}^{2}\right)$ of system's circulation tract. Here $\mathrm{Phr}=\mathrm{PL}+\mathrm{Pl}$, where $\mathrm{PL}-$ friction pressure losses along the pipeline length (L), $\mathrm{Pl}$ - local pressure losses associated with the geometry change of TCS channels.

During the harmonization of pump hydraulic characteristics and TCS circulation tract, all measures are taken in order to ensure the pressure created by pump $\mathrm{Pp}=\mathrm{H} \cdot \rho$, where $\mathrm{H}$ - pressure head $(\mathrm{J} / \mathrm{kg})$ and $\rho$ - heat transfer fluid density $(\mathrm{kg} / \mathrm{m} 3)$, being equal to hydraulic resistance of TCS tract (Phr). It means that condition $\mathrm{Pp}=\mathrm{Phr}$ under the given heat transfer fluid rate is fulfilled.

Basing on known Phr for different values of heat transfer fluid rates $(\mathrm{Q})$, TCS tract hydraulic curve $\Delta \mathrm{Phr}=\mathrm{f}(\mathrm{Q})$ shall be plotted, and then used for analyzing scheme of its harmonization with TCS pump power characteristics [11].

Frequently, the condition $\mathrm{Pp}=\mathrm{Phr}$ is not fulfilled. A standardized pump designed in a new TCS comes into operation under off-design conditions, with the heat transfer fluid rate and pressure Pp lower than it is required. This problem can be solved by means of using two pumps combined into a single unit instead of one pump. Hydraulic unit house is a base component for mounting all fixed parts of two pumps into one common unit. This design solution reduces the number of sealed joints, pump's weight and sizes. Inlet and outlet unions for hydraulic unit connection to TCS pipelines as well as a pump fitting location and seal cavities are provided on the house. 


\section{ANALYSIS OF LAYOUT OPTIONS IN A SINGLE HYDRAULIC UNIT}

There are several variants of pumps layout in a single hydraulic unit. Herein the main of them are reviewed and rationale for selecting one of the variants is stated.

\section{A. Pumps parallel layout in the hydraulic unit}

Parallel operation of two or more pumps is used when one of the pumps is not able to ensure given design flow rate Qp. Fig. 3 a) shows parallel layout of pump 1 and pump 2 in the hydraulic unit. Fig. 1 b) shows hydraulic curve of the system and head capacity curves of the pumps. Pump 1 curve is $P_{p 1}=f_{1}(Q)$; pump 2 curve is $P_{p 2}=f_{2}(Q)$. In order to obtain resultant dependence $\Sigma \mathrm{P}_{\mathrm{p}}=\mathrm{f}(\mathrm{Q})$ considering the same design $\mathrm{y}$-coordinate $\mathrm{Phr}$, $\mathrm{x}$ coordinates $\mathrm{Q}_{\mathrm{A}}$ and $\mathrm{Q}_{\mathrm{B}}$ are summarized. Intersection point of curves $\mathrm{P}_{\mathrm{hr}}=\mathrm{f}(\mathrm{Q})$ and $\Sigma \mathrm{P}_{\mathrm{p}}=\mathrm{f}(\mathrm{Q})$ designated as " $\mathrm{C}$ " symbol is operating point where design parameters have the following values: pressure difference $\mathrm{Phr}$ and flow rate $\mathrm{Q}_{\mathrm{p}}=\mathrm{Q}_{\mathrm{A}}+\mathrm{Q}_{\mathrm{B}}$.

\section{B. Pumps consequent layout in the hydraulic unit}

Consequent operation of pumps is used if the pressure difference $\Delta \mathrm{Pp}$ being ensured by one pump is insufficient at flow rate $\mathrm{Qp}=\mathrm{Q}_{\mathrm{A}}$. In this case, if the flow rate $\mathrm{Qp}$ remains unchanged, total pressure difference equal to $\Sigma \mathrm{Pp}=\mathrm{Pp} 1+\mathrm{Pp} 2$ increases. Layout implementation of TCS pumps consequent is shown in Fig. 4.

\section{Standby pump layout of in the hydraulic unit}

a)
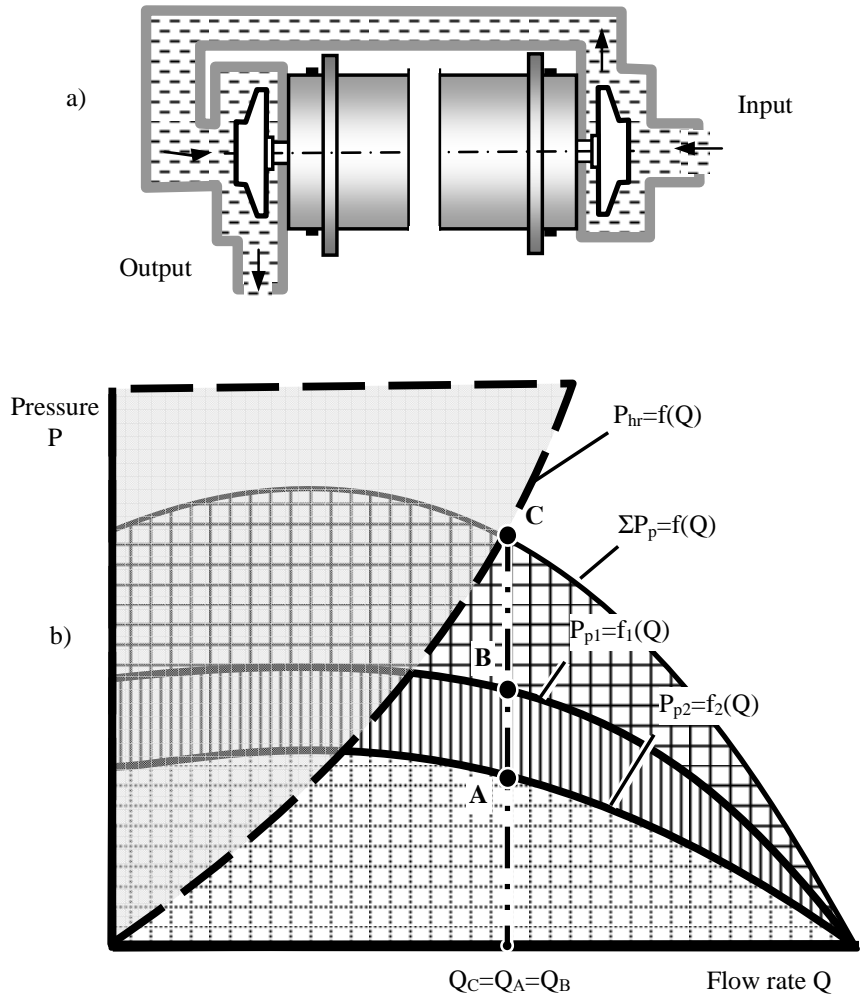

Fig. 4. A scheme of sequent layout of pumps in the hydraulic unit: a) a scheme of liquid end of the hydraulic unit; b) a curve of hydraulic characteristic harmonization
Let us review the third variant of two standardized centrifugal pumps layout in a single hydraulic unit. It is the variant with fulfilled condition $\mathrm{Pp}=\mathrm{Phr}$. In this case the hydraulic unit is used for duplication of main operating pump by another standby pump. Thus, the principle of device redundancy in order to increase TCS operation reliability is implemented. Flow direction of heat transfer fluid in the hydraulic unit is represented by its flow part scheme shown in Fig. 5. In case of pump 1 failure, for example due to the damage of bearings, the standby pump comes to operation.

The hydraulic unit is additionally supplied with an outlet header having poppet check valve 6 mounted with the degree of freedom along the axis of header 5 . When the valve moves under fluid pressure coming from operating pump 1 to header 5 , the valve closes the output form the pot of standby pump 2 and blocks the hydraulic connection between inlet header 2 and outlet header 5. Thus, heat transfer fluid flow along the ring-shaped trajectory and from output of operating pump 1 to its input through the pot of non-operating pump 2 is prevented.

\section{CONCLUSION}

Hydraulic unit structures represented in the article summarize the experiences accumulated by the Russian specialists in airspace industry. The usage of standardized centrifugal pumps in hydraulic units of aircraft thermocontrol systems allows achieving
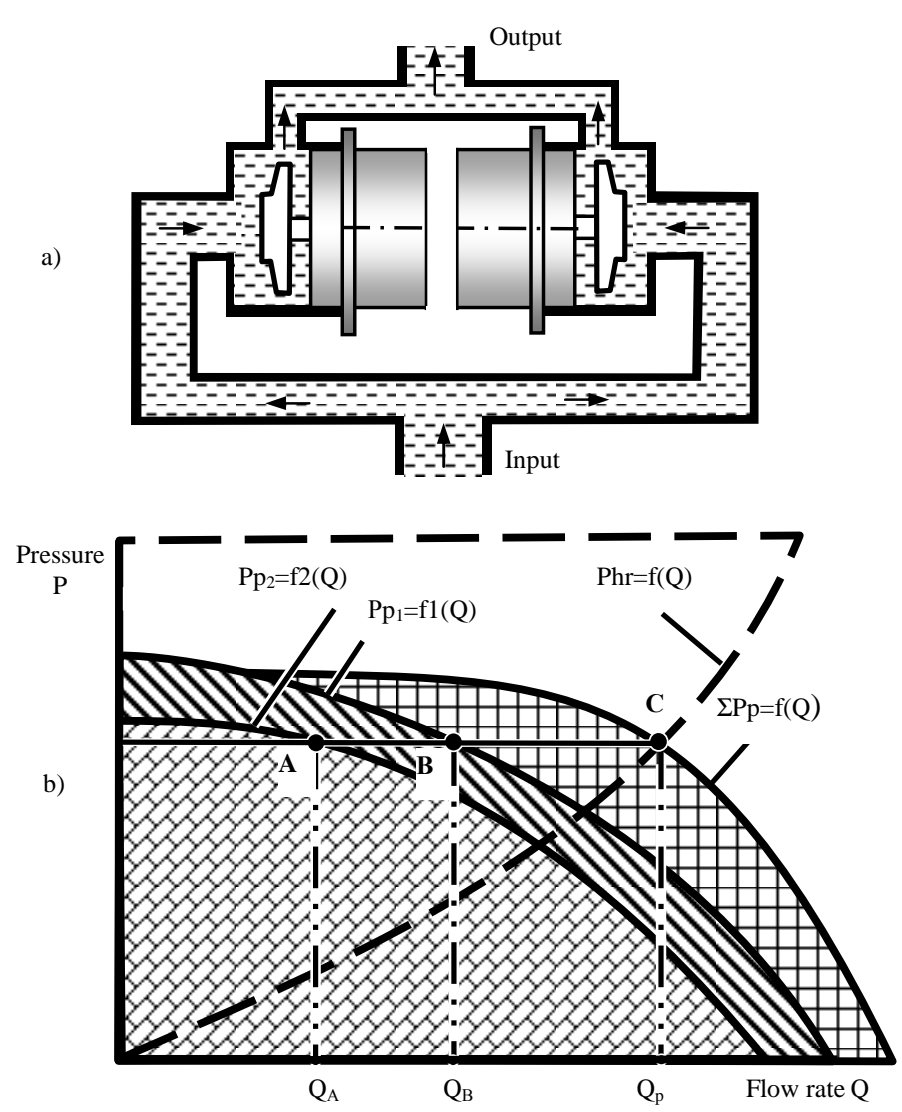

Fig. 3. Pumps' parallel layout in the hydraulic unit a) flow part of the hydraulic unit; b) hydraulic characteristics harmonization 


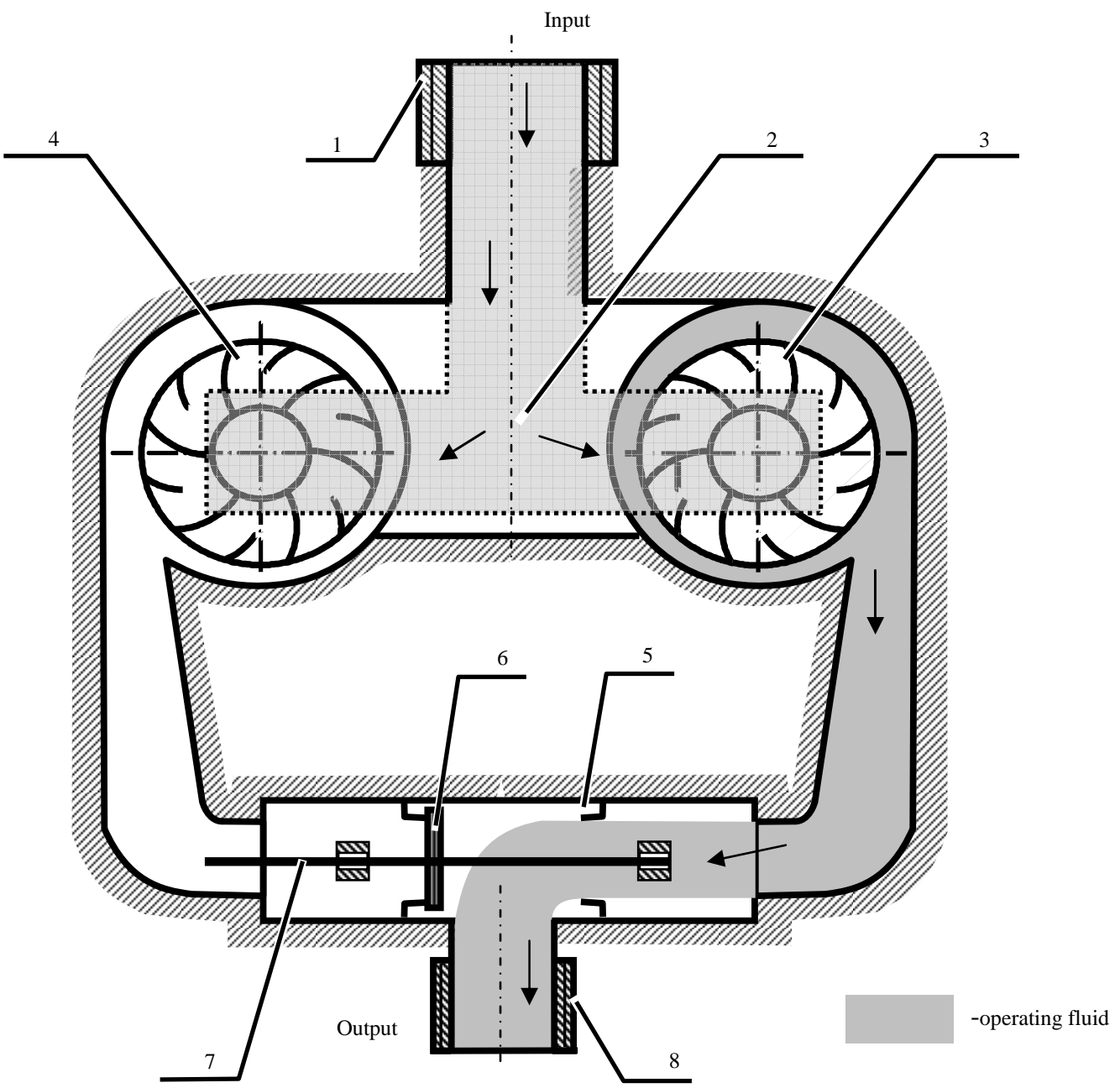

Fig.5. A scheme of a hydraulic unit flow part at standby pump layout: 1 -
inlet union; $2-$ input header; $3-$ pump 1 ;
$4-$ pump 2; $5-$ outlet header; $6-$ check valve;
7 - check valve spindle; 8 - outlet union

the following results:

- Time and cost of a new TCS design are reduced.

- Cost of TCS production is significantly reduced.

- Reliability of TCS operation increases due to both the usage of standardized pump structures got down to a fine art and installation of standby pump in the hydraulic unit.

\section{References}

[1] J. Meseguer, I. Perez-Grande, A. Sanz-Andres, Spacecraft Thermal Control, Woodhead Publishing Limited: Cambridge University Press, 2012.

[2] R. Matthijssen, P. Van put, Van der Lis, "Development of An Advanced Mechanically Pumped Fluid Loop For Thermal Control Of Large Future Telecommunication Platforms", International Conference on Environmental Systems, Chicago, pp. 72-79, 2007.

[3] A.V. Delkov, A.A. Kishkin, N.A. Lavrov, F.V. Tanasienko, "Analysis of Efficiency of Systems for Control of the Thermal Regime of Spacecraft", Chemical and Petroleum Engineering, vol. 51(9), pp. 714-719, 2016.
[4] E. Kotlyarov, P. Van put, R. Reuvers, T. Tjiptahardja, A-S.Galouye-Merino, B. Daly, P. Hugonnot, "Modelling and Correlation of an Actively Controlled Single-Phase Mechanically- Pumped Fluid Loop", Telecommunication Platforms: International Conference on Environmental Systems, Chicago, pp. 121-129, 2007.

[5] N.A. Testoyedov, V.V. Dvirniy, E.A. Morozov, G.V. Dvirny, N.V. Eremenko, "Improving the longevity of spacecraft instruments", Bulletin of the Siberian State Aerospace University, vol. 16 (2), pp. 430-437, 2015.

[6] V.E. Chebotarev, V.E. Kosenko, Fundamentals of the design of space vehicles for information suppor, Siberian State Aerospace University, 2011.

[7] D.J. Laser, J.G. Santiago, "A review of micropumps", Journal of Micromechanics and Microengineering, vol. 14 (6), pp. 35-64, 2004.

[8] M.V. Kraev, V.A. Lukin, B.V. Ovsyannikov, Low-flow pumps of aviation and space systems, Mashinostroyeniye, 1985.

[9] F. M. Yuferov, Electric machine the automatic device, High school, 1988.

[10] A.V. Bobkov, Centrifugal pumps of systems of thermoregulation of space vehicles, Dal'nauka, 2003, p. 217.

[11] K.P. Feoktistov, Space vehicles, Voyenizdat, 1983. 